\title{
IMMEDIATE LOADING IMPLANT: NEED OF HOUR: A CASE REPORT
}

\author{
Shivaprasad B. M1, Navnita Singh², Shilpa Shivanand ${ }^{3}$, Sachin B. Mangalekar ${ }^{4}$
}

\section{HOW TO CITE THIS ARTICLE:}

Shivaprasad B. M, Navnita Singh, Shilpa Shivanand, Sachin B. Mangalekar. "Immediate Loading Implant: Need of Hour: A Case Report". Journal of Evolution of Medical and Dental Sciences 2015; Vol. 4, Issue 31, April 16;

Page: 5403-5407, DOI: $10.14260 /$ jemds/2015/790

\begin{abstract}
The introduction of osseointegrated implants have revolutionized the art and science of modern dentistry giving a new lease of life to the restorative aspects in day-to-day practice. Immediate loading (IL) of dental implants can significantly decrease treatment time and thus increase patient acceptance. IL of dental implants has recently gained popularity due to several factors including reduced trauma as well as aesthetic and psychological benefits to the patient. The present case report describes the immediate replacement of partially edentulous maxilla using Nobel Active $^{\mathrm{TM}}$ implant. It describes about the diagnosis, treatment planning and procedures involving the placement of single tooth immediate implant followed by uneventful healing.
\end{abstract}

KEYWORDS: Immediate loading (IL) implants, aesthetics, Nobel Active ${ }^{\mathrm{TM}}$ implant.

INTRODUCTION: The introduction of osseointegrated implants has revolutionized the art and science of modern dentistry giving a new lease of life to the restorative aspects in day-to-day practice. It has transformed into a reliable and predictable treatment modality for fully and partially edentulous arches. Immediate loading (IL) of dental implants has recently gained popularity due to several factors including reduction in treatment time and trauma as well as aesthetic and psychological benefits to the patient. A fundamental prerequisite for implant success is substantial primary stability at the time of insertion and following loading of the implant. It may be considered as the unifying principle behind the need for adequate bone volume and density, longer or wider implants, and the 3-6-month delay recommended before implants are placed in function. ${ }^{1}$ Today immediate loading (IL) of dental implants is an eminent and acknowledged treatment strategy which is extensively being used for the rehabilitation of missing teeth. ${ }^{2,3}$ IL may be described as functional loading (With occlusal contacts) immediately after implantation (or within 3-4 days after surgery) without waiting for the healing period.4,5,6 IL has gained popularity due to less tissue trauma, reduced overall treatment time, decreased patient's anxiety and discomfort, high patient acceptance and better function and aesthetics.7,8

According to the original Brånemark protocol, dental implants, regardless of their design or system, required an undisturbed healing period of three months in mandible and six months in maxilla. While these periods purportedly allowed time for osseointegration of the implants within the respective arch, Brånemark's recommendations for healing were based on empirical data that were never scientifically proven and never experimentally ascertained. ${ }^{9}$

As implantology has experienced numerous advances in implant designs as well as the surgical and restorative techniques, many clinicians have questioned whether nonloaded healing period is still a valid prerequisite for success. Different definitions have been used to describe immediate loading, and it is difficult for one to arrive at a clear understanding of the involved materials and clinical requisites. The present case report describes about the diagnosis, treatment planning and clinical procedures involving the immediate loading implant. 
A CASE REPORT: A 34 years old male patient visited a private clinic with a chief complaint of missing upper right back tooth region since 8 months and wanted immediate replacement of the same. Clinical examination revealed healthy gingiva and periodontium. Patient was systemically healthy, non-smoker, non-bruxer and desired for dental implant placement. Intraoral periapical radiograph was advised to determine the dimension of the residual alveolar bone. Based on the dimension of the available bone, implant size was estimated to be $10 \mathrm{~mm}$ X $5 \mathrm{~mm}$. Patient was aesthetically more concerned and wanted immediate implant placement along with the prosthesis. Considering the available bone quantity and patient's expectation, placement of NOBEL ACTIVE implant of 10mm X $5 \mathrm{~mm}$ was planned.

A surgical stent was fabricated using an auto-polymerizing acrylic resin. The surgery was performed under $2 \%$ lignocaine as local anesthetic. Infraorbital, greater palatine nerves were blocked along with local infiltration. After ensuring adequate local anesthesia, crestal incision was given which was extended as the sulcular incision up to minimum of one tooth adjacent to the edentulous space on either side. Buccal and palatal flap was reflected more than $5 \mathrm{~mm}$ beyond the crest of the alveolar ridge. Sequences of the drills were used according to manufacturer's instruction and the last drill used was $4.2 \mathrm{~mm}$ as the diameter of the selected implant was $5 \mathrm{~mm}$. The implant was placed (Fig. 1) in the osteotomy site using the implant carrier and was driven up to $10 \mathrm{~mm}$ using the wrench. After placing the implant in position, the torque was ascertained not less than $35 \mathrm{Ncm}$ for primary stability to be eligible for immediate loading. IOPAR was taken to ensure parallelism of the implant to adjacent root (Fig. 2).

The suitable abutment was placed in position and interdental papillae were sutured with figure of eight sutures. Temporary crown (acrylic) was placed in position and was allowed for proper healing of the soft tissues, especially around interdental papilla. Patient was advised not to brush vigorously, chew hard food from the surgical side for one week. After one week, uneventful healing of the tissues was observed at the site of implant placement and the temporary crown was removed including the sutures. An impression was made with addition silicone for the permanent crown to be prepared in the laboratory. Porcelain fused to metal crown with the access hole (Fig. 3 and Fig. 4) was placed in position using glass ionomer luting cement. Clinical photographs and radiographs are provided.

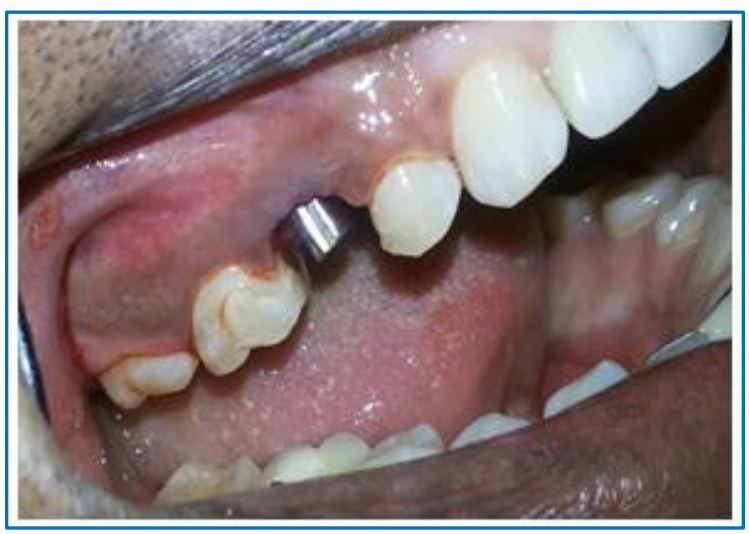

Fig. 1: Post-Operative

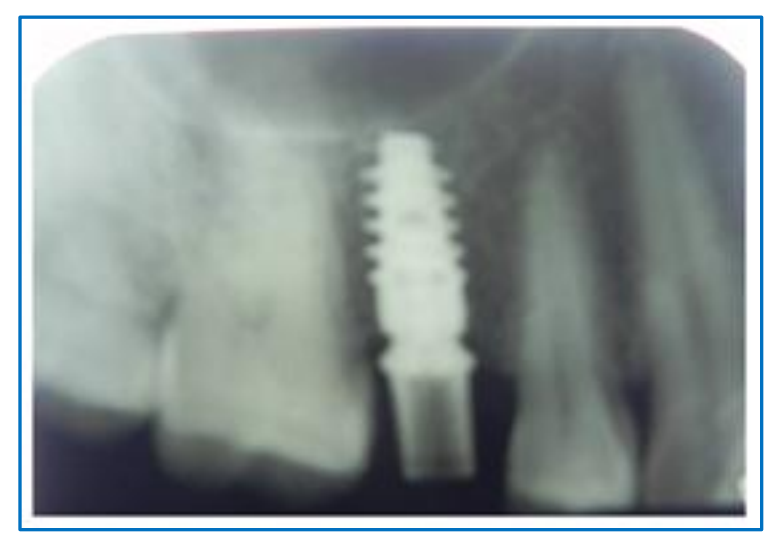

Fig. 2: Radiograph showing implant in position 


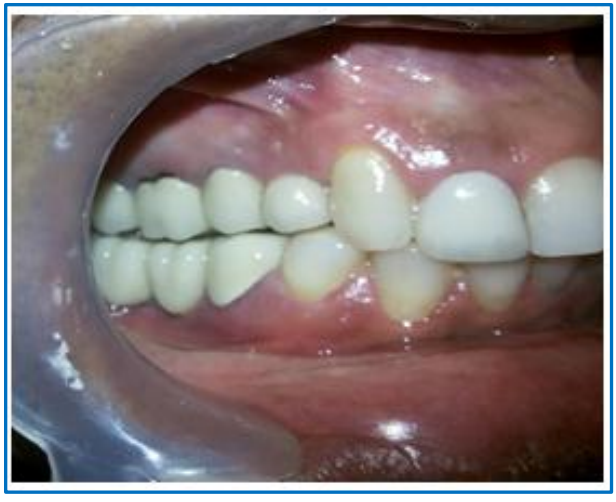

Fig. 3: Porcelain fused to metal Crown in position (lateral view)

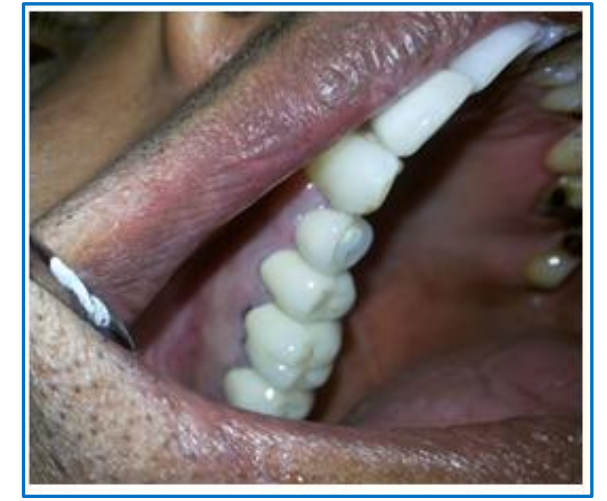

Fig 4: Porcelain fused to metal with access hole (Occlusal view)

DISCUSSION: Immediate loading of oral implants has been defined as a situation where the superstructure is attached to the implants no later than $72 \mathrm{hr}$ after surgery. ${ }^{10}$ The definition of immediate loading also includes occlusion with the teeth of the opposite jaw. Under these conditions, successful immediate loading of screw-type dental implants has been reported as early as 1979.11

Several experimental studies have shown that immediate loading of threaded implants does not necessarily lead to fibrous tissue healing. Several different indications for immediate loading have been discussed. They range from implant placement in the edentulous mandible and maxilla to single tooth applications in extraction sockets.

Traditionally, the density of compact bone provides good initial stabilization for the installed implant, while cancellous bone provides much reduced density and thereby a strategy for achieving initial stability for each site is recommended. To facilitate stability in softer bone qualities, the body of the Nobel Active ${ }^{\mathrm{TM}}$ implant is used here as it is tapered, further enhanced by threads that increase in vertical thickness as insertion proceeds to condense bone. The combination of these features, combined with the possibility for under-preparation of site diameter in soft bone, allow for achievement of substantial stability also in predominantly cancellous bone sites.

The amount of bone available for implant retention differs from site to site. The implant is "active" enabling an angle change during insertion. This ability for redirection allows the implant to be inserted into available bone, for example within the palatal wall of an anterior extraction socket, and then be redirected for maximal stabilization while establishing proper restorative alignment. The special narrowing of the implant collar diameter allows for favorable ridge adaptation when crestal ridge width is limited. ${ }^{12}$

High success rates from immediately loaded implants in humans were first documented in the middle 1980s, when the 1-stage implant protocol gained popularity. Babbush et al. (1986) reported a cumulative success rate of $88 \%$ on 1739 immediately loading TPS implants. ${ }^{13}$ It is widely accepted that immediate loading is a desirable procedure, if the outcome in terms of implant survival and success is comparable with that of conventional loading.

CONCLUSION: Within the limits of the present case report the data indicate that immediate loading of single-tooth implants in the posterior maxilla is a reliable method for replacement of missing teeth. 
Future studies will have to evaluate long-term data of immediate restorations on implants and possible applications of this technique in situations where problems of poor bone quality, multiple implants or augmentation procedures must be overcome.

\section{REFERENCES:}

1. Romanos GE. Surgical and prosthetic concepts for predictable immediate loading of oral implants. Journal of the California dental association 2004; 32: 991-1001.

2. Romanos GE, Testori T, Degidi M, Piattelli A. Histologic and histomorphometric findings from retrieved, immediately occlusally loaded implants in humans. Journal of Periodontology 2005; 76: 1823-32.

3. Pen arrocha M, Boronat A, Garcia B. Immediate loading of immediate mandibular implants with a full-arch fixed prosthesis: a preliminary study. Journal of Oral and Maxillofacial Surgery 2009; 67: 1286-93.

4. Araujo MG, Sukekava F, Wennstrom J, Lindhe J. Ridge alterations following implant placement in fresh extraction sockets: an experimental study in the dog. Journal of Clinical Periodontology 2005; 32: 645-52.

5. Raghoebar GM, Schoen P, Meijer HJ, Stellingsma K, Vissink A. Early loading of endosseous implants in the augmented maxilla: a 1-year prospective study. Clinical Oral Implants Research 2003; 14: 697-702.

6. Degidi M, Piattelli A. 7-Year follow-up of 93 immediately loaded titanium dental implants. Journal of Oral Implantology 2005; 31: 25-31.

7. Hui E, Chow J, Li D, Liu J, Wat P, Law H. Immediate provisional for single-tooth implant replacement with Branemark system: preliminary report. Clinical Implant Dentistry and Related Research 2001; 3: 79-86.

8. Chaushu G, Chaushu S, Tzohar A, Dayan D. Immediate loading of single-tooth implants: immediate versus nonimmediate implantation. A clinical report. International Journal of Oral and Maxillofacial Implants 2001; 16: 267-72.

9. Branemark PI. Zarb GA, Albrektsson T. Tissue integrated prosthesis. Osseointegration in clinical dentistry. Chicago: Quintessence, 1985.

10. Aparicio, C., Rangert, B. \& Sennerby, L. (2003) Immediate/early loading of dental implants: a report from the Sociedad Espanola de Implantes World Congress consensus meeting in Barcelona, Spain, 2002. Clinical Implant Dentistry and Related Research 5: 57-60.

11. Ledermann, P. D. (1979) Stegprothetische Versorgung des zahnlosen Unterkiefers mit Hilfe von plasmabeschichteten Titanschraubenimplantaten. Deutsche Zahnärztliche Zeitschrift 34: 3-7.

12. http: //removpros. dentistry. dal. ca/RemovSite/Implants_files/Nobel\%20BioActive\%20Smaller\%20\%26\%20Stronger. pdf

13. Babbush, C. A., Kent, J. N. \& Misiek, D. J. Titanium plasma-sprayed (TPS) screw implants for the reconstruction of the edentulousmandible. Journal of Oral \& Maxillofacial Surgery 44: 274-282. 


\section{AUTHORS:}

1. Shivaprasad B. M.

2. Navnita Singh

3. Shilpa Shivanand

4. Sachin B. Mangalekar

\section{PARTICULARS OF CONTRIBUTORS:}

1. Reader, Department of Periodontology, Raja Rajeswari Dental College and Hospital, Bangalore.

2. Post Graduate Student, Department of Periodontology, Raja Rajeswari Dental College and Hospital, Bangalore.

3. Post Graduate Student, Department of Periodontology, Raja Rajeswari Dental College and Hospital, Bangalore.

\section{FINANCIAL OR OTHER} COMPETING INTERESTS: None
4. Professor, Department of Periodontology, Maitri College of Density and Research Centre, Anjora, Durg, Chhattisgarh.

\section{NAME ADDRESS EMAIL ID OF THE CORRESPONDING AUTHOR:}

Dr. Shivaprasad B. M,

Reader,

Raja Rajeswari Dental College and Hospital, \#14, Ramohalli Cross,

Kumbalgodu, Mysore Road,

Bangalore-560074.

E-mail: drshivaprasad2008@yahoo.co.in

Date of Submission: 27/02/2015. Date of Peer Review: 28/02/2015. Date of Acceptance: 04/04/2015. Date of Publishing: 16/04/2015. 